Article

\title{
Experimental and Numerical Analyses on Mixing Uniformity of Water and Saline in Pipe Flow
}

\author{
Bin Sun ${ }^{1}$, Yuanbo Lu ${ }^{1}$, Quan Liu ${ }^{1}$, Hongyuan Fang ${ }^{1,2,3, *}$, Chao Zhang ${ }^{1, *}$ (i) and Jinping Zhang ${ }^{1}$ \\ 1 School of Water Conservancy Engineering, Zhengzhou University, Zhengzhou 450001, China; \\ sunbin@zzu.edu.cn (B.S.); 18137852539@163.com (Y.L.); lq15207204451@163.com (Q.L.); \\ zhjp@zzu.edu.cn (J.Z.) \\ 2 National Local Joint Engineering Laboratory of Major Infrastructure Testing and Rehabilitation Technology, \\ Zhengzhou 450001, China \\ 3 Collaborative Innovation Center of Water Conservancy and Transportation Infrastructure Safety, \\ Zhengzhou 450001, China \\ * Correspondence: 18337192244@163.com (H.F.); chao.zhang.zzu@outlook.com (C.Z.); \\ Tel.: +86-183-3719-2244 (H.F.); +86-371-6778-0116 (C.Z.)
}

Received: 30 May 2020; Accepted: 10 August 2020; Published: 13 August 2020

check for updates

\begin{abstract}
Liquid-liquid mixing is commonly observed in many applications such as the chlorination of water supplies and the agricultural fertigation. In order to study the mixing law of water-chlorine or water-fertilizer in a turbulent pipeline, saline was selected as a tracer injected into the pipeline. In this paper, the computational fluid dynamics (CFD) software was employed to study flow fields in water-saline pipelines. Four variates (mixing ratio $\delta$, pipe diameter $D$, volume flow rate in the main pipe $Q$, saline density $\rho_{s}$ ) were considered to investigate the effects of multiple variates on mixing uniformity. The coefficient of variation (COV) was selected as the evaluation index of mixing uniformity, effective mixing length ( $L_{E M L}$, the distance from the saline inlet to the fully mixed position) was chosen to quantitatively analyze the fully mixed position of water and saline in pipelines. The results of this numerical model agree well with experimental measurements and it shows that this model can effectively predict the concentration field of water and saline in the pipeline. Based on the experimental and simulated results, it was found that for the fixed mixing ratio, saline density and volume flow rate, the values of $L_{E M L}$ increased significantly with increasing pipe diameters. Furthermore, dimensional analysis (D-A) was adopted to examine the influences of the four variates on $L_{E M L}$, and their correlation coefficient of the curve-fitting equation was calculated to be 0.996 .
\end{abstract}

Keywords: concentration distribution; dimensional analysis; effective mixing length; numerical simulation; pipe flow

\section{Introduction}

Liquid-liquid mixing, as a complex nonlinear system, is commonly observed in many industrial applications. Some examples include the chlorination of water supplies [1] and the identification of a single pollution source in the water supply pipe network [2,3], the online mixing of water and fertilizer in the agricultural fertigation [4], and the different gas-liquid/oil-water two-phase flow structure [5]. Simultaneous mixing of liquid-liquid in pipes presents considerable challenges and difficulties due to the complexity of the two liquid streams' mixing processes. Conventional mixing devices include a venturi-type mixer, batch mixer, and screw mixer. However, their use may require a disruption of the flow or the energy required and the possible maintenance problems for mixers or obstructions in a pipe.

One viable alternative is to use the pipeline as a mixing chamber by injecting the substance into the pipe flow. The method is sometimes referred to as pipe-flow mixing, in-line mixing, or mixing-on-the-fly. 
This method does not require the use of mixing units fixed in the pipe to change the flow state of the fluid to achieve good mixing, which is mainly focused on how and when one liquid diffuses into the other liquid. The effects of injection layout and structure on mixing uniformity have been widely investigated in the recent years. Zughbi [6] investigated mixing uniformity for miscible fluids in pipelines with the mesh size and turbulence model [7]. Ger and Holley [8] evaluated the given degree of mixing under three single-point injections (a center line source, a wall source, and a jet at the wall), both experimentally and numerically and stated that a jet injection resulted in production of the most rapid mixing. Fitzgerald and Holley [9] carried out their studies on jets located on the pipe wall and found that the proper angles and dual jet injection can yield a proper mixing uniformity. Forney and Lee [10] examined the effects of the ratio of jet to tube velocity and diameter on effective penetration and mixing, and the correlation of reliable data with a theory based on the study of mixing uniformity [11] was found.

Although fundamental mixing characteristics under different operating conditions and geometries have been reported by the researchers above, the complexity of the characteristics of the pipe-flow mixing process mean that the quantitative study of this process has still been inadequate. With the help of rapid development of computer technology, the computational fluid dynamics (CFD) method has been employed as an effective means in studying the mixing uniformity inside the pipe-flow mixing. In this paper, four variates (mixing ratio, pipe diameter, volume flow rate and saline density) were considered to investigate the effects of multiple variates on mixing uniformity by experimentation and simulation. Further, the coefficient of variation (COV) was selected as the evaluation index of mixing uniformity in order to quantitatively analyze the fully mixed position of pipe-flow mixing.

\section{Materials and Methods}

\subsection{The Experimental Set-Up}

\subsubsection{Experimental Purpose and Equipment}

Experiments were conducted to investigate the effect of different main pipe diameters, volume flow rates, saline densities and mixing ratios on hydraulic characteristics and mixing uniformity for the pipe-flow mixing system. As experimental setup consisting of a main pipe and a side-tube of $8 \mathrm{~mm}$ in diameter is attached to the main pipe as shown in Figure 1. To enable the sampling along the pipeline, the sampling tubes were constructed. Based on practical engineering, polyethylene (PE) pipe parameters were considered for the designed water pipeline. According to the standard dimension ratio (SDR) of 11.0 with a nominal pressure of $1.6 \mathrm{MPa}$, the pipe diameters $(D=51.4 \mathrm{~mm}, 61.4 \mathrm{~mm}$, and $73.6 \mathrm{~mm}$ ) of the main pipeline were selected [12]. For the secondary stream, water solution of sodium chloride $(\mathrm{NaCl})$ was chosen as a tracer salt. Considering safety and economy, the values of flow velocity were chosen in the range of $0.5 \sim 2 \mathrm{~m} \cdot \mathrm{s}^{-1}$ with mixing ratios $(\delta=$ jet flow rate/volume flow rate) of $0.5 \%$ and $1 \%$ (See Table 1 ). 


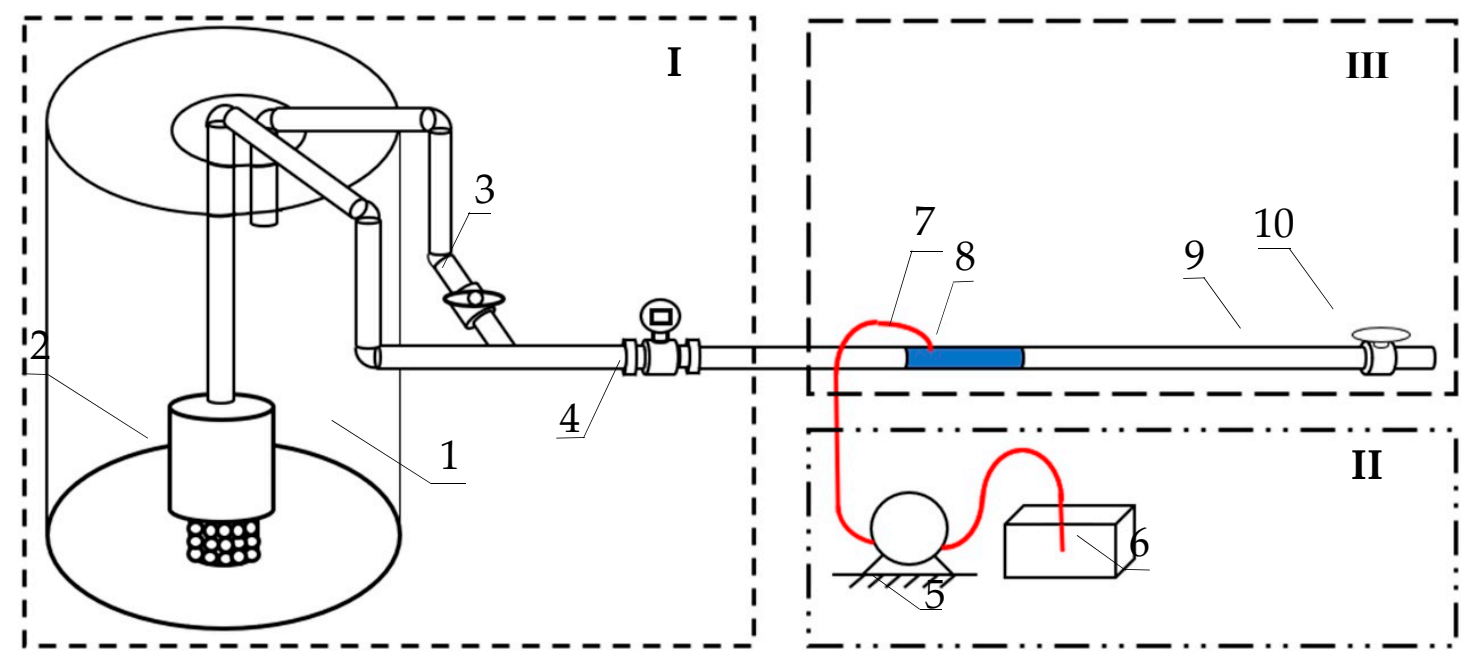

(a) Schematic diagram

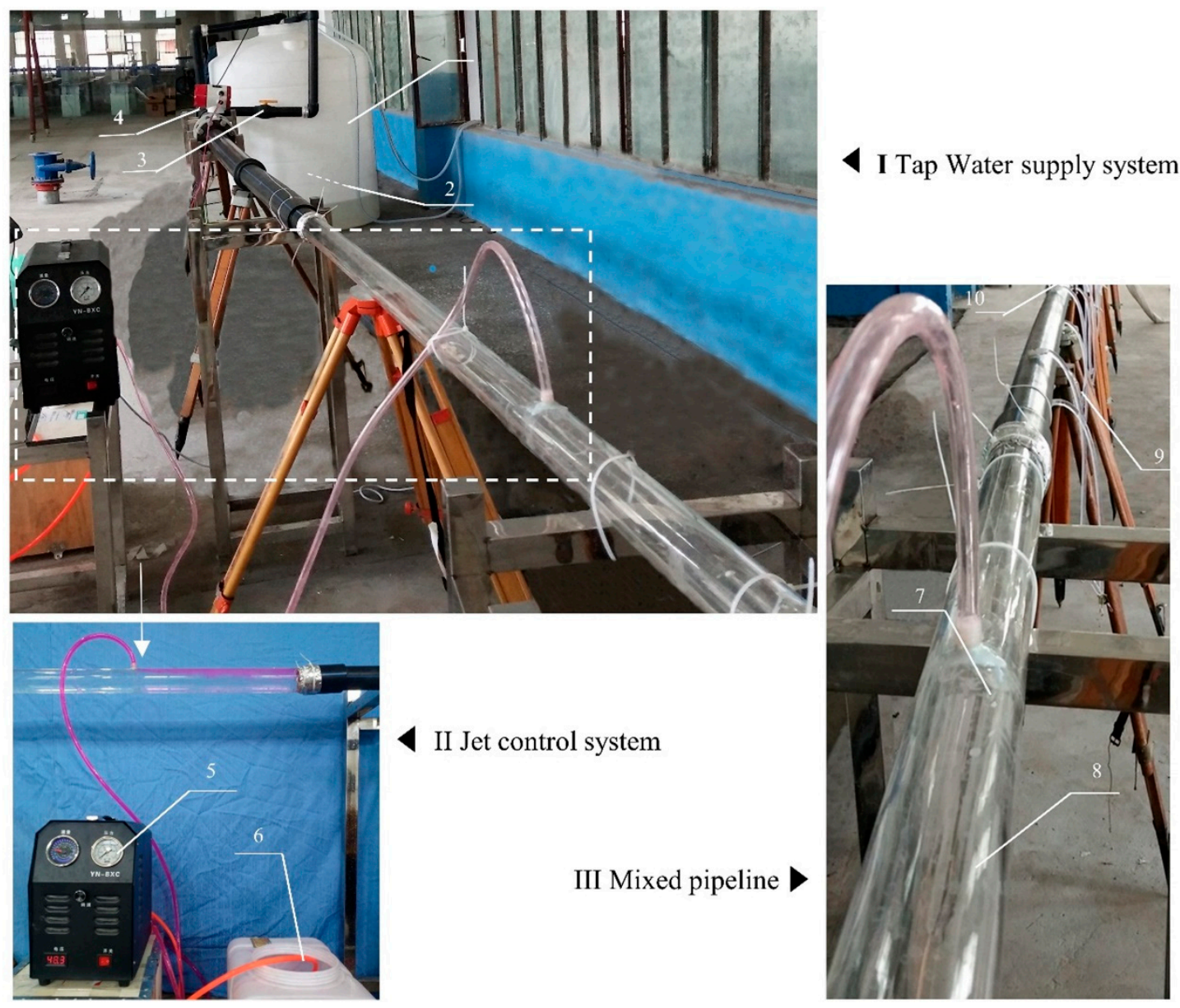

(b) Layout of test equipment

Figure 1. Experimental setup: (a) schematic diagram and (b) layout of test equipment (I-tap water supply system, II-jet control system, III-mixed pipeline; 1,6-plastic water tank; 2,5-centrifugal pump; 3,10-ball valve; 4-electromagnetic flowmeter; 7-jet inlet; 8-acrylic visible pipe; 9-polyethylene (PE) pipe). 
Table 1. Working conditions for the experiment design.

\begin{tabular}{|c|c|c|c|c|c|c|c|c|c|}
\hline No. & $\delta$ & $D(\mathrm{~mm})$ & $Q\left(\mathrm{~m}^{3} \cdot \mathrm{h}^{-1}\right)$ & $R_{e}$ & No. & $\delta$ & $D(\mathrm{~mm})$ & $Q\left(\mathrm{~m}^{3} \cdot \mathrm{h}^{-1}\right)$ & $R_{e}$ \\
\hline 1 & \multirow{6}{*}{$1 \%$} & \multirow{6}{*}{51.4} & 4 & 30,847 & 19 & \multirow{6}{*}{$0.5 \%$} & \multirow{6}{*}{51.4} & 4 & 30,847 \\
\hline 2 & & & 6 & 46,270 & 20 & & & 6 & 46,270 \\
\hline 3 & & & 8 & 61,694 & 21 & & & 8 & 61,694 \\
\hline 4 & & & 10 & 77,117 & 22 & & & 10 & 77,117 \\
\hline 5 & & & 12 & 92,541 & 23 & & & 12 & 92,541 \\
\hline 6 & & & 14 & 107,964 & 24 & & & 14 & 107,964 \\
\hline 7 & \multirow{6}{*}{$1 \%$} & \multirow{6}{*}{61.4} & 6 & 38,735 & 25 & \multirow{6}{*}{$0.5 \%$} & \multirow{6}{*}{61.4} & 6 & 38,735 \\
\hline 8 & & & 9 & 58,102 & 26 & & & 9 & 58,102 \\
\hline 9 & & & 12 & 77,469 & 27 & & & 12 & 77,469 \\
\hline 10 & & & 15 & 96,836 & 28 & & & 15 & 96,836 \\
\hline 11 & & & 18 & 116,204 & 29 & & & 18 & 116,204 \\
\hline 12 & & & 21 & 135,571 & 30 & & & 21 & 135,571 \\
\hline 13 & \multirow{6}{*}{$1 \%$} & \multirow{6}{*}{73.6} & 8 & 43,085 & 31 & \multirow{6}{*}{$0.5 \%$} & \multirow{6}{*}{73.6} & 8 & 43,085 \\
\hline 14 & & & 12 & 64,628 & 32 & & & 12 & 64,628 \\
\hline 15 & & & 16 & 86,170 & 33 & & & 16 & 86,170 \\
\hline 16 & & & 20 & 107,713 & 34 & & & 20 & 107,713 \\
\hline 17 & & & 24 & 129,256 & 35 & & & 24 & 129,256 \\
\hline 18 & & & 28 & 150,798 & 36 & & & 28 & 150,798 \\
\hline
\end{tabular}

\subsubsection{Testing Sequence}

To simulate the concentration distribution along the pipeline under different working conditions, the following experiments are designed:

(1) System control involved adjusting the volume flow rate $Q$ through a ball-valve opening, and control of the jet flow rate $q$ through a control knob to change the motor speed and achieve the mixing ratio $\delta$. In the design of the pipeline experimental system and simulated working conditions, the design flow and pipe diameter in the relevant design specifications were combined, as well as the real engineering conditions were simulated as far as possible considering the scale effect. Table 1 shows the working conditions of proposed design and Reynolds numbers of the main pipelines. In this study, various concentrations of saline were considered, including $1 \%, 2 \%, 4 \%, 6 \%$ and $8 \%$. The concentration of saline used in the experiments was $1 \%$, correspondingly, and other concentrations were simulated as controls.

(2) Tap water was applied in the pipeline system during the initial $10 \mathrm{~min}$ to stabilize the system and then saline was injected into the system through a centrifugal pump until the mixing was finished. Saline, as a tracer, is safe, non-toxic, soluble in water and does not influence the properties of groundwater, as well as having high stability and detection capability. In addition, the conductivity of saline with different concentrations is significantly different from that of water, which can meet the test requirements. As can be seen in Figure 2, samples were collected at P0-P14 and each point consisted of upper wall point (UW) and lower wall point (LW). When the inlet pressure and flow reached stability, the solution in the sampling points was collected, and the electrical conductivity (EC) was measured at thirty points. Every sampling solution was measured three times, and ninety data were obtained for each working condition. Considering the influence of temperature on EC, an EC meter and a temperature meter were used for the measurement, and the temperature-conductivity indicator had the function of automatic temperature compensation. 

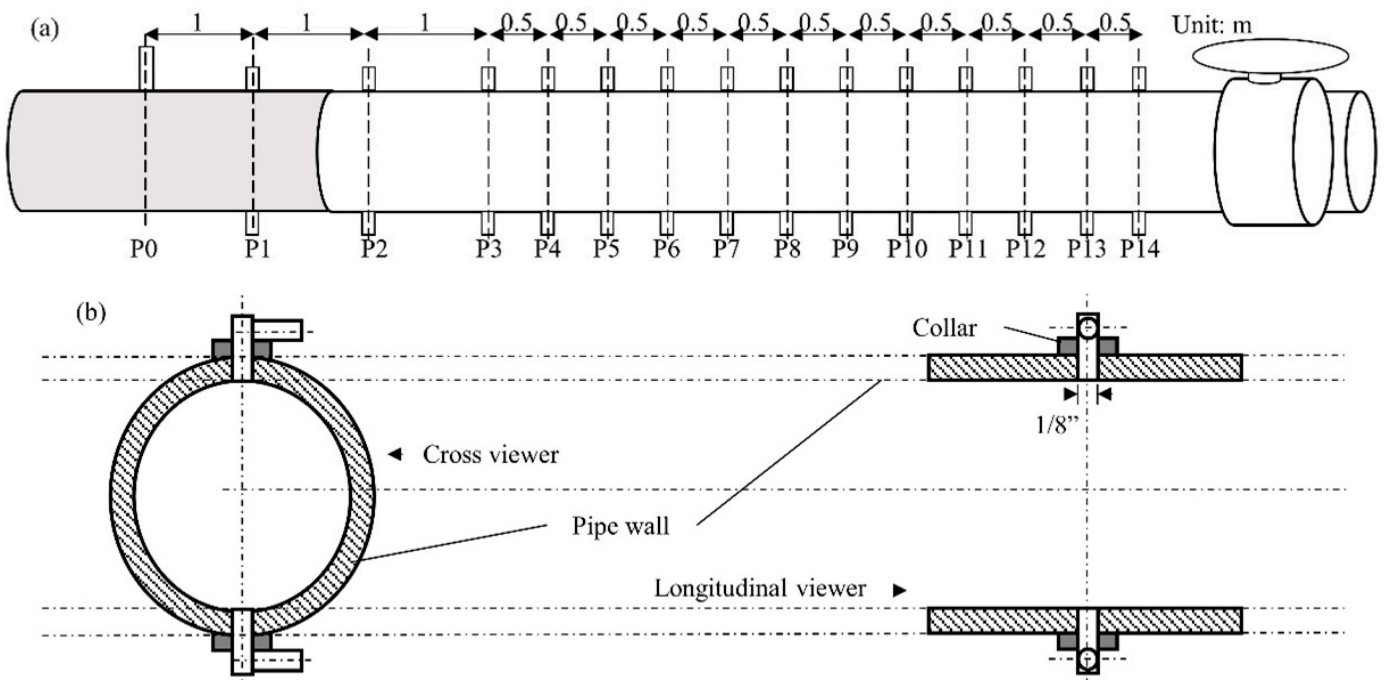

Figure 2. (a) The sampling point arrangement, (b) schematic diagram of sampling tube.

\subsection{The Numerical Model}

\subsubsection{Geometric Model}

A geometry identical to the experimental test pipe section was constructed. The length of the proposed pipeline model was $10 \mathrm{~m}$, and the vertical jet inlet (inlet 2) of $8 \mathrm{~mm}$ diameter was placed at a distance of $1.5 \mathrm{~m}$ from the cross-flow inlet (inlet 1) (See Figure 3a). The CFD module of Ansys software, which is the most popular finite element analysis software in the field of fluid mechanics, was used in the model construction and calculation.

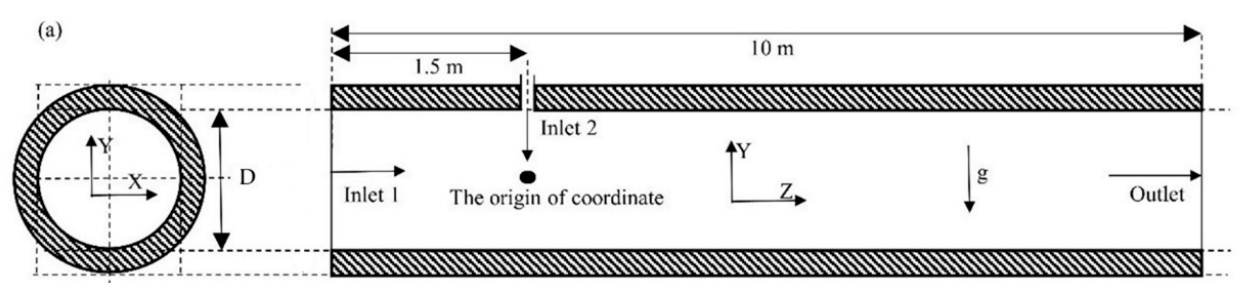

(b)

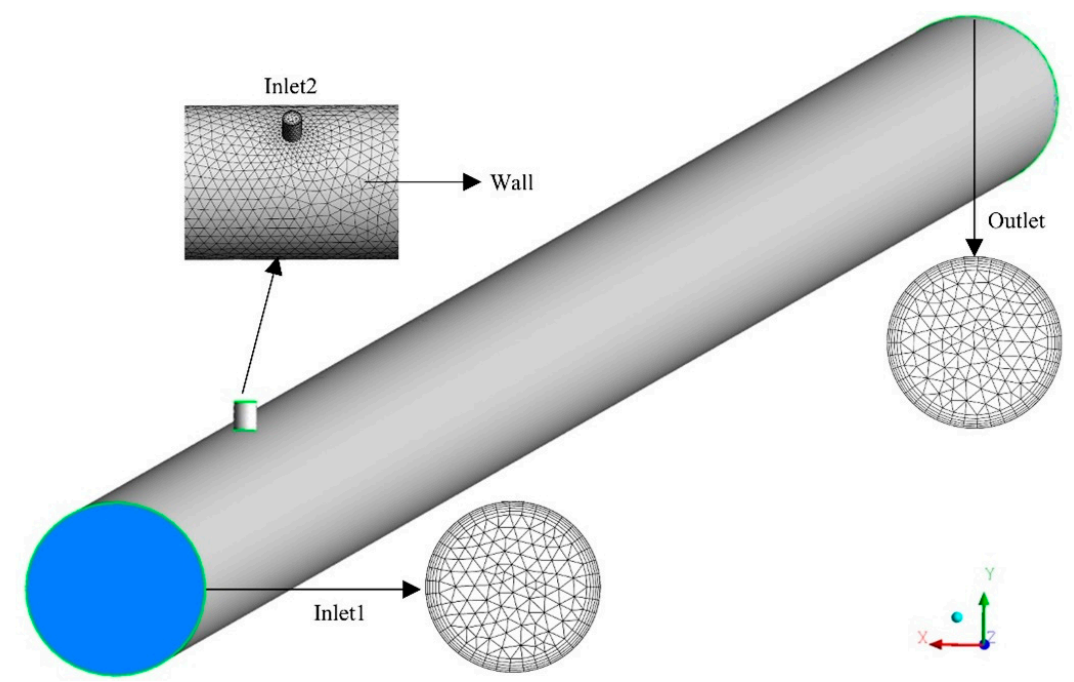

Figure 3. (a) Schematic of the mixing system, (b) geometric dimensions with numerical grid for model A. 
According to the pipeline parameters presented in Table 1, three 3-dimensional flow region models (A, B, and C) were developed using tetra meshes (total numbers of cells were 1,838,167, 2,498,301, and $3,453,428$, respectively). In order to improve the computational accuracy, a local grid refinement method was proposed. The pipeline geometry with numerical mesh for model A is presented in Figure $3 b$.

\subsubsection{Governing Equation}

The mixing process was considered as two liquid mixing processes under turbulent flow. The turbulence model was developed based on the renormalization group (RNG) k- $\varepsilon$ model $[13,14]$ and various liquid mixing models adopted the mixture model [15], which can effectively simulate the strong coupling isotropic fluids [16]. The continuity equation is expressed as follows:

$$
\frac{\partial}{\partial t}\left(\rho_{m}\right)+\nabla \cdot\left(\rho_{m} \bar{v}_{m}\right)=0
$$

with

$$
\begin{gathered}
\bar{v}_{m}=\frac{\sum_{k=1}^{n} \varphi_{k} \rho_{k} \bar{v}_{k}}{\rho_{m}} \\
\rho_{m}=\sum_{k=1}^{n} \varphi_{k} \rho_{k}
\end{gathered}
$$

where $k$ is the number of fluid phases in the model, $\rho_{k}$ is the density of $k, \varphi_{k}$ is the volume fraction of $k, \bar{v}_{k}$ is the average velocity of $k$, and $\nabla \cdot\left(\rho_{m} \bar{v}_{m}\right)$ is the mass flux of surface area of the control body. The momentum equation was developed as follows.

$$
\frac{\partial}{\partial t}\left(\rho_{m} \bar{v}_{m}\right)+\nabla \cdot\left(\rho_{m} \bar{v}_{m}{ }^{2}\right)=-\nabla P+\nabla \cdot\left[\mu_{m}\left(\nabla \bar{v}_{m}+\nabla \bar{v}_{m}{ }^{T}\right)\right]+\rho_{m} g+f
$$

where $\mu_{m}$ is the viscosity coefficient of the mixture, $g$ denotes gravitational acceleration, and $f$ signifies volume force. The k-phase volume fraction was formulated as follows [17]:

$$
\frac{\partial}{\partial t}\left(\varphi_{k} \rho_{k}\right)+\nabla \cdot\left(\varphi_{k} \rho_{k} \bar{v}_{m}\right)=-\nabla \cdot\left(\varphi_{k} \rho_{k} \bar{v}_{d r, k}\right)
$$

with

$$
\bar{v}_{d r, k}=\bar{v}_{k}-\bar{v}_{m}
$$

where $\bar{v}_{d r, k}$ is the drift velocity of $k$ and $\bar{v}_{k}$ is the velocity of mixed-phase flow.

\subsubsection{Boundary Conditions}

The entrance and the outlet of the calculation domain were designed based on velocity-inlet and outflow boundary conditions, respectively. The absolute roughness of PE pipes is $0.01 \mathrm{~mm}$, and the material characteristics were set the same in the simulation. The wall treatment method selected the standard wall function method with the fixed non-slip surface. The physical parameters and their corresponding boundary types are presented: the density of water in inlet 1 was $997.05 \mathrm{~kg} \cdot \mathrm{m}^{-3}$, and the viscosity was $0.89008 \mathrm{mPa} \cdot \mathrm{s}$; the density and viscosity of saline in inlet 2 varied with concentrations of saline.

This study referred to the simulation methods of some classical fluid mechanics cases to set up the simulation process, the main parameters in the solver were set as follows: the PRESTO format was adopted for pressure, the first-order upwind style discretization was selected for momentum, volume phase fraction, and turbulent kinetic energy [18], and the second-order upwind style discretization was employed to calculate the turbulence dissipation rate. In addition, the couple algorithm was chosen 
to solve Equations (1)-(6), and the turbulence intensity $(I)$ and the turbulence length scale $(L)$ were calculated based on the following empirical relationships [19]:

$$
\begin{aligned}
I & =\frac{0.16}{R e^{1 / 8}} \\
L & =0.07 D_{h}
\end{aligned}
$$

where $D_{h}$ is the characteristic dimension and $R_{e}$ is the Reynolds number at the inlet. All calculations were performed using a steady-state solver with a convergence precision of $1 \times 10^{-6}$.

\subsubsection{Data Processing}

In this paper, liquid-liquid mixing refers to the uniform distribution of water and saline in a pipeline. The COV method and the relative standard deviation (RSD) method are often used to evaluate the mixing performance [20]. In the current paper, COV was selected as the evaluation index of multi-phase flow:

$$
\mathrm{COV}=\frac{\mathrm{s}}{\overline{\bar{c}}}
$$

where $s$ is the standard deviation of saline-phase fraction on the cross section, which can be calculated by the concentration of all nodes on the cross section.

$$
\begin{gathered}
s=\sqrt{\frac{1}{N} \sum_{i=1}^{N}\left(c_{i}-\bar{c}\right)^{2}} \\
\bar{c}=\frac{c_{1}+c_{2}+c_{3}++c_{N}}{N}
\end{gathered}
$$

where $N$ is the total number of sampling points, $c_{i}$ is the volume fraction of saline-phase at each node, and $\bar{c}$ is the average value of saline-phase volume fraction on the section. It was noticed that a lower COV value resulted in more homogeneous mixing. Ideally, in the beginning of the mixture, the standard deviation is high, the mixture parameter $\mathrm{COV}$ is also high, and the mixture parameter $\mathrm{COV}$ is close to zero in the mixed completion section. In this study, the electrical conductivity of the mixed solution was measured in the experiments, which determined the uniform mixing position in the experiments.

\subsection{Model Validation}

\subsubsection{Calibration of the Relationship between EC and Concentration}

The relationship between EC, volume fraction (VF) and solution concentration (C) is shown in Figure 4. In CFD software, solution concentration can be expressed by volume fraction. As shown in Figure 4, the relationship among electrical conductivity, volume fraction, and concentration of saline solution was established. The preferred relationship between compensated EC and VF of saline was linear and the fitting degree was 0.998 , which indicated that this equation fitted the measured data well and can be used to calculate the VF of saline in each sampling point. 


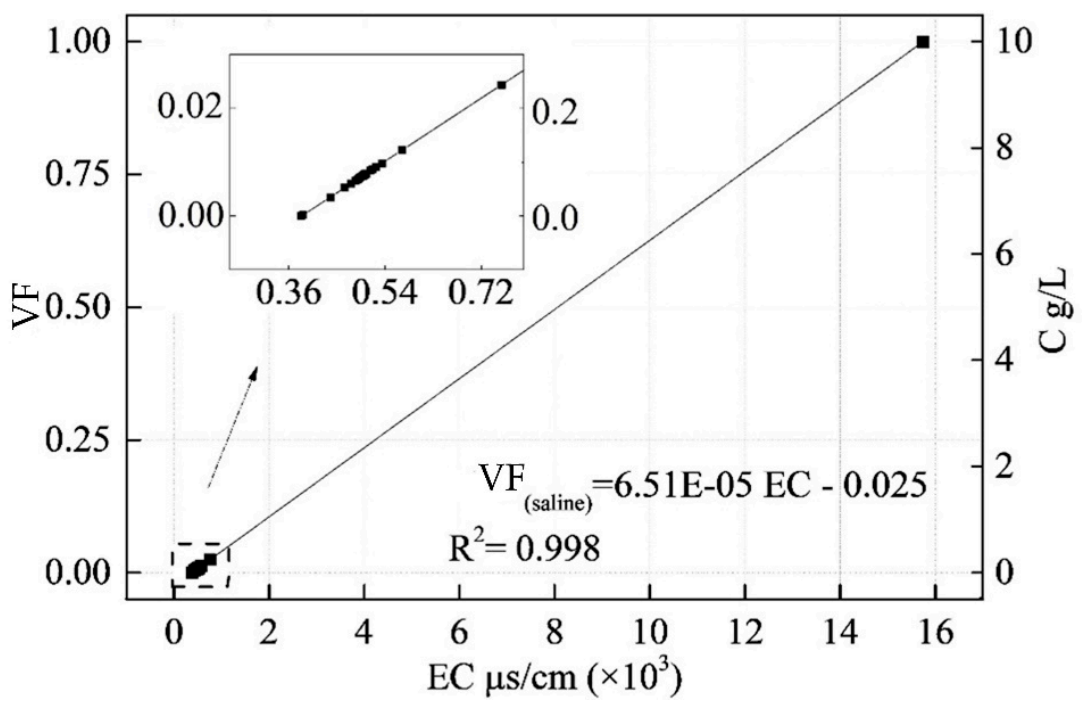

Figure 4. Relationship among electrical conductivity (EC), volume fraction (VF) and concentration (C) of saline solution.

\subsubsection{Comparison of Numerical and Experiment Data}

The simulation was verified by comparing the numerical results with the experimental results. To take the comparison results of pipeline with No.5, No.9, and No.14 as examples, Figure 5 shows the UW and LW points of experimental and numerical values of concentration versus location along the pipeline, and the results for the experimental (Exp.) and numerical simulations (Sim.) are indicated with different symbols and lines (See Figure 5).

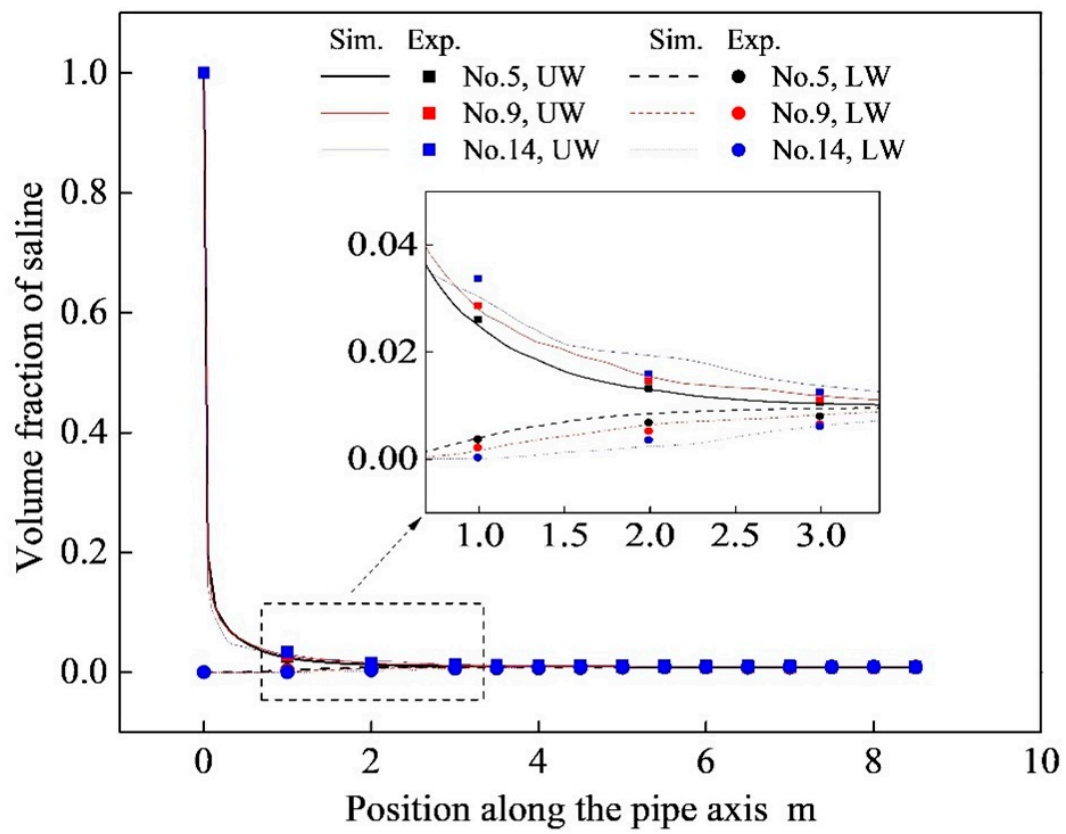

Figure 5. Comparison of experimental and simulated results for No.5, No.9, and No.14.

The figure shows that the numerical results of VF of saline location along the UW and LW pipe line agree well with experimental results; meanwhile, the maximum relative error and the average error were within the allowable range. Moreover, the experimental data have the same variation trend as the simulated data. The trends of the VF of the saline on the UW decrease from large to small while 
those on the LW are opposite, which further indicated that numerical simulations were feasible for solving the mixing problem of the second phase in the main pipeline.

\section{Results}

\subsection{Mixing Process and Concentration Analysis}

The simulated result of No.36 was selected as an example to examine the mixing process of water and saline. The CFD analysis for concentration distribution is illustrated in Figure 6. Figure 6 shows concentration contours in a lengthwise-sectional plane along the axis of the pipeline. Before the injection of saline at inlet 2, water filled the whole volume, and after injection, saline started to mix with water. The mixing zone gradually expanded along the opposite direction of the pipe axis. After injection, the concentration of the mixture gradually increased along the Z-axis and simultaneously, decreased along the $Y$-axis. Further, the concentration difference between each horizontal liquid layer gradually decreased under the mixing of water and saline.

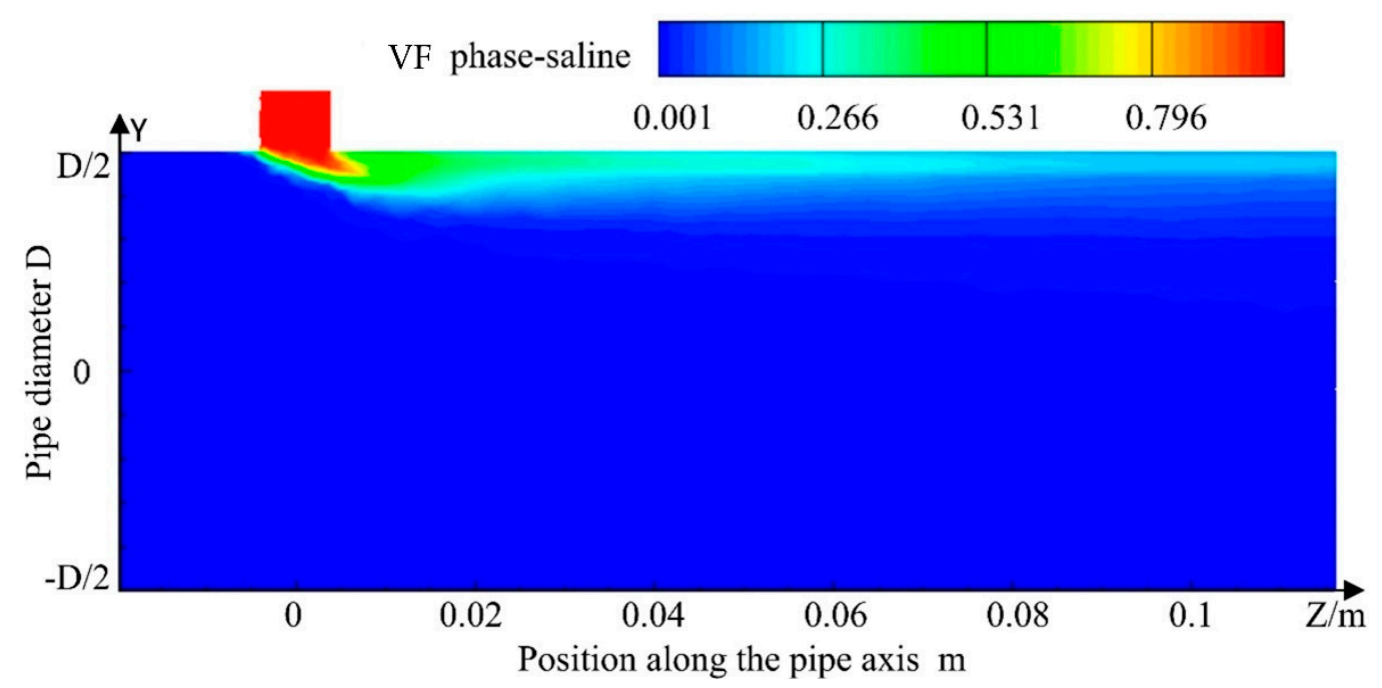

Figure 6. Contour of concentration distribution (VF phase-saline) in the pipeline.

According to the Figure 6, the initial concentration field of the mixed liquid was relatively concentrated and it will take a longer distance to mix well. This could be further explained by looking at Figure 7. Figure 7 shows concentration contours in cross-sectional planes at various distances downstream of the pipeline.

Before the injection of the saline, water was filled in the entire pipeline; hence, the concentration remained constant. However, after the injection of the saline, the concentration near the upper wall first decreased sharply along the direction of cross-flow, then increased slowly, and finally, tended to be stable. Further, along the Z-axis, the concentration difference between each cross section gradually decreased and eventually, became stable.

Due to the small flow rate of saline, the flow characteristics of the mixed solution are greatly affected by the volume flow rate when saline is injected into the main pipe. The Reynolds number $(R e)$ is necessary for pipe flow to further analyze the research results by judging the flow state of the fluid [21]. The $R_{e}$ values of the main pipes all greatly exceed 2300, which indicated the flow in the main pipe is turbulent and has obvious turbulent characteristics. In the turbulent state, the particles in the mixed solution are mixed with each other and move in a disorderly manner, and have strong energy dissipation capability and diffusivity, which has significant impact on the mixing of solutions in the pipes. 


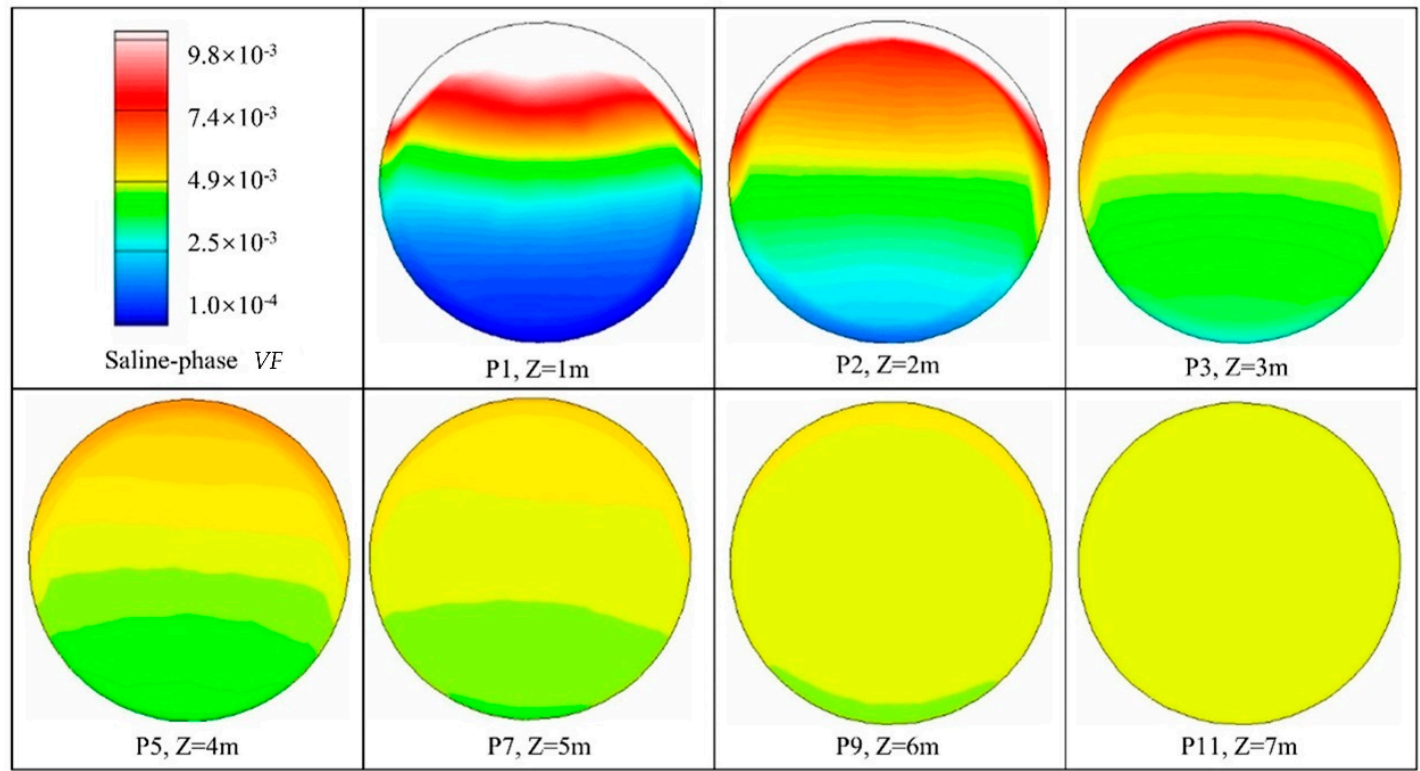

Figure 7. Contours of concentration in cross-sectional planes in the Z-axis.

\subsection{Factors Influencing Mixing Process}

Considering a pipe diameter $(D)$ of $61.4 \mathrm{~mm}$ as a constant, the influence of volume flow rate $(Q)$ and mixing ratio $(\delta)$ on the mixing process was analyzed (Figure 8 ). Figure 8 shows the plot of the mixing index COV versus pipe axis with $Q$ and $\delta$ as two parameters for the case where $D=61.4 \mathrm{~mm}$. It can be seen from the figure that an increase in pipe axis position led to a decrease in mixing index. In the same pipe axis position, when $Q$ was kept constant, an increase in $\delta(0.5 \%$ to $1 \%)$ led to a bigger decrease in index COV; however, when $\delta$ was a constant, an increase in $Q\left(18 \mathrm{~m}^{3} \cdot \mathrm{h}^{-1}\right.$ to $\left.21 \mathrm{~m}^{3} \cdot \mathrm{h}^{-1}\right)$ led to a smaller increase in index COV.

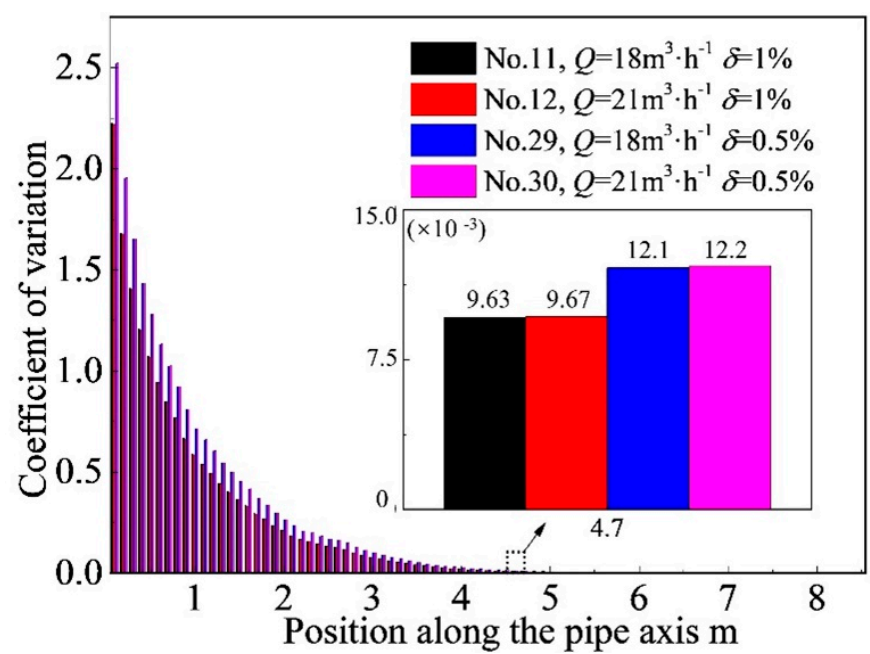

Figure 8. Mixing index coefficient of variation $(\mathrm{COV})$ as a function of the pipe axis of injection for $D=61.4 \mathrm{~mm}$ with various volume flow rates $(Q)$ and mixing ratios $(\delta)$.

Figure 9 shows the concentration contours of the pipeline model with $Q=12 \mathrm{~m}^{3} \cdot \mathrm{h}^{-1}$ and $\delta=1 \%$ for $D_{1}=51.4 \mathrm{~mm}, D_{2}=61.4 \mathrm{~mm}$, and $D_{3}=73.6 \mathrm{~mm}$. It can be seen from the figure when $Q$ and $\delta$ were kept constant, an increase in $D$ led to a longer mixing distance. In other words, mixing index COV increased with the increase in $D$ in uniform position. 


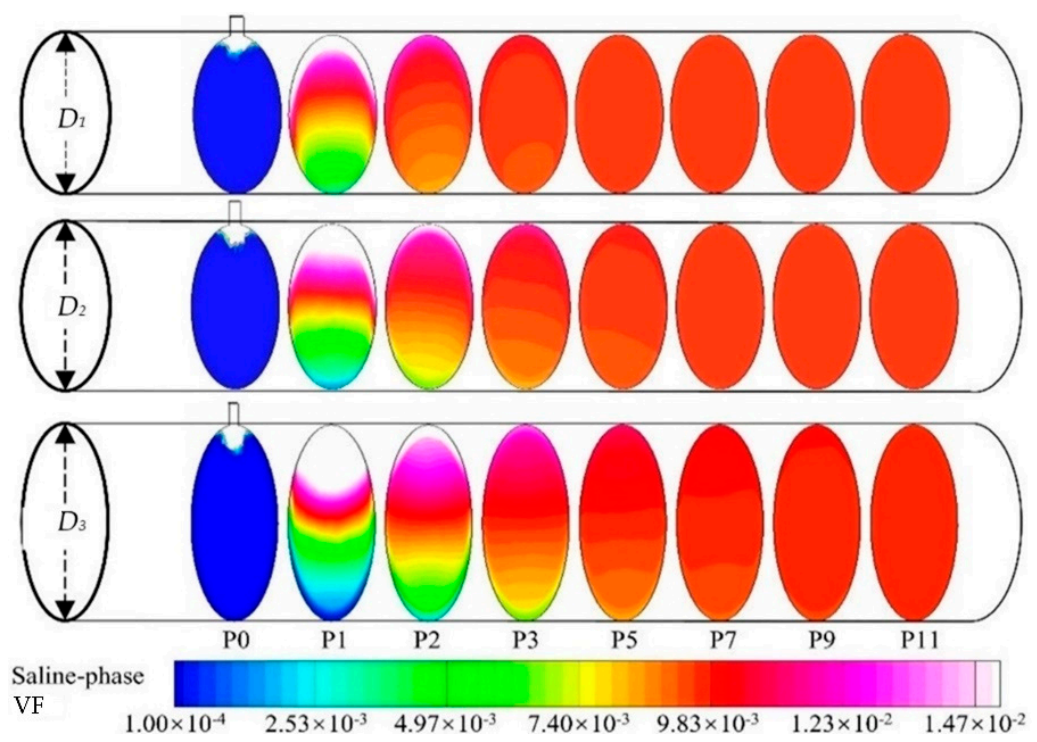

Figure 9. Saline-phase concentration contours of the pipeline with three of diameters: $I=D_{1}=51.4 \mathrm{~mm}$; $I=D_{2}=61.4 \mathrm{~mm} ; I=D_{3}=73.6 \mathrm{~mm}$.

According to the definition of $\mathrm{COV}$, a value of zero implies that the saline solution is homogeneous, and a high COV implies a high degree of heterogeneity. Therefore, the mixing condition could be improved by decreasing volume flow rate $(Q)$ and pipe diameter $(D)$, and meanwhile increasing mixing ratios $(\delta)$.

In the quantitative analysis, the concentration value of each cross-section of numerical simulation was substituted into Equation (10) in order to calculate the mixing index COV. Figure 10 shows the variation of $\mathrm{COV}$ along the pipe axis for NO.32. When COV value is less than 0.01 (the point of mixing uniformity in Figure 10), the COV difference between each cross section was found to be negligible; hence, this point was considered as the completion of the mixing process. The distance from the saline-phase inlet to the fully mixed position was defined as the effective mixing length, or ' $L_{E M L}$ ' for short. Hence, in this working condition, the value of $L_{E M L}$ was found to be $6.62 \mathrm{~m}$. In subsequent data processing, $\mathrm{COV}=0.01$ is used as the critical value to determine $L_{E M L}$ [22].

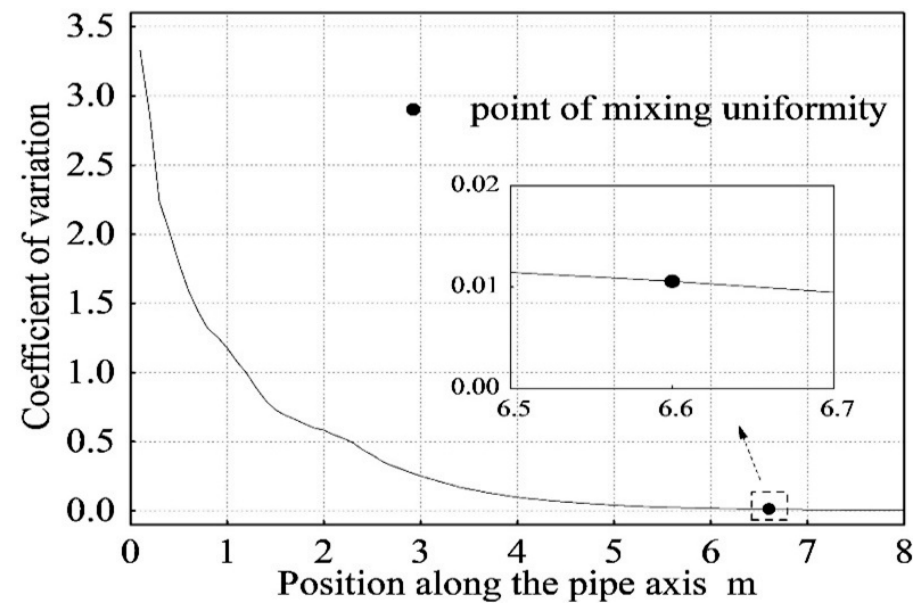

Figure 10. COV in cross-sectional planes in the pipeline at NO.32.

Figure 11 shows the effect of saline density on $L_{E M L}$. It can be observed that the effective mixing length decreases accordingly with the increase in saline density when other conditions remain the same. The simulated results of experimental working conditions were shown in Table 2. Further, dimensional analysis was adopted to examine the influences of the variates on $L_{E M L}$. 


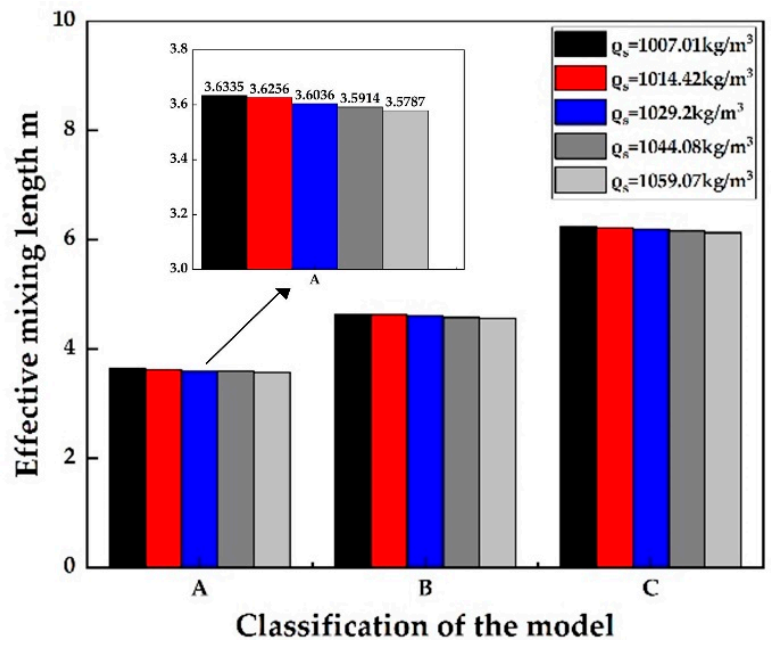

Figure 11. Variation tendency of effective mixing length $\left(L_{E M L}\right)$ under different saline densities.

Table 2. The simulated results of experimental working conditions.

\begin{tabular}{cccccccc}
\hline No. & $L_{E M L}(\mathrm{~m})$ & No. & $L_{E M L}(\mathrm{~m})$ & No. & $L_{E M L(\mathrm{~m})}$ & No. & $L_{E M L(\mathrm{~m})}$ \\
\hline 1 & 3.5778 & 10 & 4.6580 & 19 & 3.7818 & 28 & 4.8471 \\
2 & 3.6335 & 11 & 4.6688 & 20 & 3.8272 & 29 & 4.8504 \\
3 & 3.6388 & 12 & 4.6719 & 21 & 3.8328 & 30 & 4.8534 \\
4 & 3.6414 & 13 & 6.1609 & 22 & 3.8356 & 31 & 6.5525 \\
5 & 3.6452 & 14 & 6.2353 & 23 & 3.8374 & 32 & 6.6248 \\
6 & 3.6487 & 15 & 6.2363 & 24 & 3.8420 & 33 & 6.6455 \\
7 & 4.5986 & 16 & 6.2461 & 25 & 4.7770 & 34 & 6.6522 \\
8 & 4.6437 & 17 & 6.2541 & 26 & 4.8311 & 35 & 6.6533 \\
9 & 4.6555 & 18 & 6.2581 & 27 & 4.8430 & 36 & 6.6630 \\
\hline
\end{tabular}

\subsection{Dimensional Analysis of the Effective Mixing Length}

Dimensional analysis can qualitatively and quantitatively describe physical phenomena, reveal the regular relationship between physical quantities, and solve the criterion relationship when problems cannot be described by a differential equation. In order to clarify the structural relationship and explore the significance level of each factor, the main physical quantities that affect the physical process must be correctly determined on the basis of full understanding $[23,24]$. In this section, the dimensional analysis was adopted to derive the equation of $L_{E M L}$ and a total of eight physical quantities including effective mixing length $\left(L_{E M L}\right)$, pipe diameter $(D)$, mixing ratio $(\delta)$, the flow velocity of inlet $1(v)$, water density $\left(\rho_{w}\right)$, dynamic viscosity $(\mu)$, gravitational acceleration $(g)$, and density difference of water and saline $\left(\Delta \rho, \Delta \rho=\rho_{s}-\rho_{w}\right)$ were considered in order to obtain the dimensionless relationship.

$$
f\left(D, v, \mu, \rho_{w}, g, \Delta \rho, L_{E M L}, \delta\right)=0
$$

where $D, v$, and $\mu$ are the basic physical quantity, $\delta$ is the dimensionless quantities, thus the range of dimensional matrix is three. The dimensionless $\pi$ relationship was expressed according to Equation (13).

$$
F\left(\pi_{1}, \pi_{2}, \pi_{3}, \pi_{4}, \pi_{5}, \pi_{6}, \pi_{7}, \pi_{8}\right)=0
$$


Further, $\pi_{1}=\pi_{2}=\pi_{3}=1, \pi_{8}=\delta$, the obtained value of $\pi_{4-7}$ from $\pi$ theorem was formulated.

$$
\left\{\begin{aligned}
\pi_{4} & =\frac{\rho_{w}}{D^{-1} \times \mu \times v^{-1}} \\
\pi_{5} & =\frac{g}{D^{-1} \times v^{2}} \\
\pi_{6} & =\frac{\Delta \rho}{D^{-1} \times \mu \times v^{-1}} \\
\pi_{7} & =\frac{L_{E M L}}{D}
\end{aligned}\right.
$$

The following relationships were obtained.

$$
\pi_{7}=\frac{L_{E M L}}{D}=F_{2}\left(1,1,1, \frac{\rho_{w} \times D \times v}{\mu}, \frac{g \times D}{v^{2}}, \frac{\Delta \rho \times D \times v}{\mu}, \delta\right)
$$

Then, Equation (15) can be transformed into the following form.

$$
\frac{L_{E M L}}{D}=a \times\left(\frac{\rho_{w} \times D \times v}{\mu}\right)^{b} \times\left(\frac{g \times D}{v^{2}}\right)^{c} \times\left(\frac{\Delta \rho \times D \times v}{\mu}\right)^{d} \times \delta^{e}
$$

with

$$
\left\{\begin{array}{l}
v=\frac{4 \times Q}{D^{2} \times \pi} \\
\operatorname{Re}=\frac{\rho \times D \times v}{\mu} \\
A r=\frac{g \times D^{3} \times \rho_{w} \times\left(\rho_{s}-\rho_{w}\right)}{\mu^{2}}
\end{array}\right.
$$

where $a, b, c, d$ and e are coefficients, Re denotes Reynolds number, Ar is Archimedes number [25,26].

Now, by fitting the data of each set of working condition data, the coefficient values in Equation (16) were obtained, and the equation was simplified accordingly.

$$
\left\{\begin{array}{l}
\frac{L_{E M L}}{D}=0.9992 \times Q^{-0.36444} \times D^{0.9111} \times g^{0.18222} \times R e^{0.37266} \times A r^{-0.00885} \times \delta^{-0.07497} \\
R^{2}=0.996
\end{array}\right.
$$

where $L_{E M L}$ is effective mixing length, $D$ represents main pipe diameter, $Q$ is volume flow rate, $g$ is gravitational acceleration, $R e$ denotes the Reynolds number of the main pipe, $A r$ is Archimedes number.

The simulation parameters of each working condition were substituted into Equation (18), and the obtained results were compared with numerical simulation findings and experimental findings. It was found that the results of dimensional analysis (D-A) were very close to numerical simulation findings, the maximum relative error did not exceed $3.29 \%$, the minimum relative error was $0.24 \%$, and the average error was $1.34 \%$. Figure 12 demonstrates a comparison of $L_{E M L}$ obtained by experiment and the calculation, which further indicates that using the Equation (18) could predict the accurate $L_{E M L}$ and has a potential to be applied in practice. The equation further verified the conclusion of the analysis of influencing factors, moreover, it can be seen that the Reynolds number and Archimedes number have a significant effect on the mixing efficiency in pipeline turbulent mixing. 


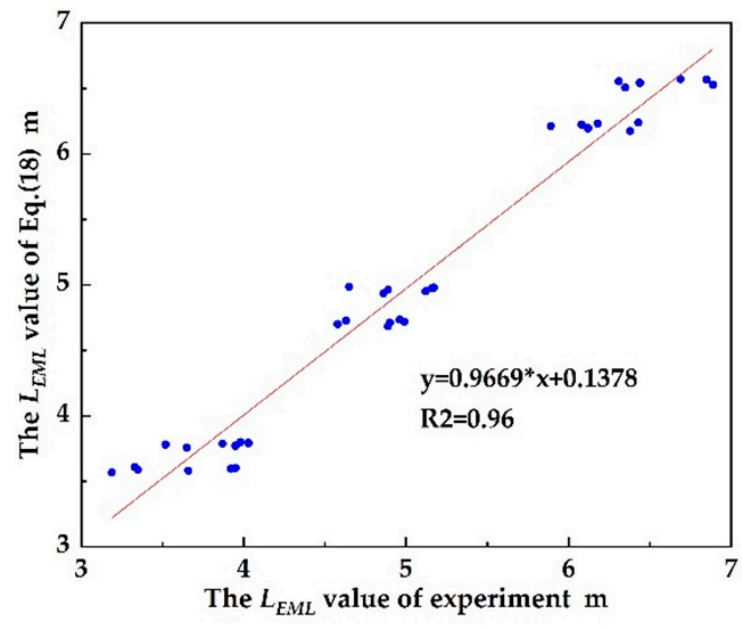

Figure 12. Comparison of $L_{E M L}$ between our model and experimental results.

\section{Conclusions}

In this study, the mixing uniformity of vertical jet saline in cross-flow pipelines was analyzed using CFD and experiments. The analytical solution $L_{E M L}$ at different volume flow rates, mixing ratios, saline densities and pipe diameters was also evaluated. The main conclusions are as follows:

(1) The concentration distribution of the numerical simulation agrees well with experimental measurements which indicated that using the commercial software and the established numerical model were feasible for solving the mixing problem of the second phase in main pipeline.

(2) For the fixed mixing ratio and saline density, the values of $L_{E M L}$ started to decrease with decreasing pipe diameters or volume flow rates, thus smaller pipe diameters and volume flow rates manifested high saline mixing efficiencies. Similarly, for the fixed pipe diameters and volume flow rates, it shows the inverse relation between the mixing ratio, saline density and $L_{E M L}$.

(3) Dimensional analysis was employed to examine the influence of the four variates (mixing ratio, pipe diameter, saline density and volume flow rate) on $L_{E M L}$, and the fitting degree of the methods was larger than 0.95 . It was found that the results of D-A were very close to numerical simulation findings; the maximum relative error did not exceed $3.29 \%$, the minimum relative error was $0.24 \%$, and the average error was $1.34 \%$. Therefore, it can be inferred that a D-A equation could accurately predict the mixing uniformity in the proposed piping system.

Author Contributions: Conceptualization, B.S.; Data curation, C.Z. and J.Z.; Formal analysis, Q.L. and H.F.; Funding acquisition, B.S.; Methodology, B.S.; Resources, C.Z. and J.Z.; Software, Q.L. and H.F.; Validation, Q.L. and H.F.; Writing—original draft, Y.L.; Writing-review and editing, Y.L. and C.Z. All authors have read and agreed to the published version of the manuscript.

Funding: This research was supported by the National Key Research and Development Program of China (Grant No. 2016YFC0802400), the National Natural Science Foundation of China (Grant No. 51909242, 51978630 and 51678536), the Program for Science and Technology Innovation Talents in Universities of Henan Province (Grant No. 19HASTIT043), and the Outstanding Young Talent Research Fund of Zhengzhou University (Grant No.1621323001), for which the authors are grateful.

Conflicts of Interest: The authors declare no conflict of interest. 


\section{Nomenclature}

$\begin{array}{llll}A r & \text { Archimedes number } & N & \text { total number of sampling points } \\ \mathrm{C} & \text { solution concentration }(\mathrm{g} / \mathrm{L}) & q & \text { jet flow rate }\left(\mathrm{m}^{3} / \mathrm{h}\right) \\ \mathrm{COV} & \text { coefficient of variation } & Q & \text { volume flow rate }\left(\mathrm{m}^{3} / \mathrm{h}\right) \\ D_{h} & \text { characteristic dimension }(\mathrm{m}) & R_{e} & \text { Reynolds number } \\ D & \text { pipe diameter }(\mathrm{mm}) & v & \text { flow velocity }(\mathrm{m} / \mathrm{s}) \\ \mathrm{EC} & \text { electrical conductivity (us/cm) } & \text { VF } & \text { volume fraction } \\ I & \text { turbulence intensity } & \rho_{w} & \text { water density }\left(\mathrm{kg} / \mathrm{m}^{3}\right) \\ g & \text { gravitational acceleration }\left(\mathrm{m} / \mathrm{s}^{2}\right) & \rho_{s} & \text { saline density }\left(\mathrm{kg} / \mathrm{m}^{3}\right) \\ k & \text { number of fluid phases } & \mu & \text { dynamic viscosity }\left(\mathrm{N} \cdot \mathrm{s} / \mathrm{m}^{2}\right) \\ L & \text { turbulence length scale }(\mathrm{m}) & \delta & \text { mixing ratio } \\ L_{E M L} & \text { effective mixing length }(\mathrm{m}) & \Delta \rho & \text { density difference }\left(\mathrm{kg} / \mathrm{m}^{3}\right)\end{array}$

\section{References}

1. Samadi, F.; Kruzic, A.; Prabakar, S. An Investigation of Monochloramine ReCOVeries under Different Mixing Condition. In Proceedings of the World Environmental and Water Resources Congress 2019, Pittsburgh, PA, USA, 19-23 May 2019; pp. 160-172.

2. Hartmann, J.; van der Aa, M.; Wuijts, S.; de Roda Husman, A.M.; van der Hoek, J.P. Risk governance of potential emerging risks to drinking water quality: Analysing current practices. Environ. Sci. Policy 2018, 84, 97-104. [CrossRef]

3. Stanev, V.G.; Iliev, F.L.; Hansen, S.; Vesselinov, V.V.; Alexandrov, B.S. Identification of release sources in advection-diffusion system by machine learning combined with Green's function inverse method. Appl. Math. Model. 2018, 60, 64-76. [CrossRef]

4. Tang, P.; Li, H.; Issaka, Z.; Chen, C. Effect of manifold layout and fertilizer solution concentration on fertilization and flushing times and uniformity of drip irrigation systems. Agric. Water Manag. 2018, 200, 71-79. [CrossRef]

5. Cheng, L.; Ribatski, G.; Thome, J.R. Two-phase flow patterns and flow-pattern maps: Fundamentals and applications. Appl. Mech. Rev. 2008, 61. [CrossRef]

6. Zughbi, H.D. Effects of Jet Protrusion on Mixing in Pipelines with Side-tees. Chem. Eng. Res. Des. 2006, 84, 993-1000. [CrossRef]

7. Zughbi, H.D.; Khokhar, Z.H.; Sharma, R.N. Mixing in pipelines with side and opposed tees. Ind. Eng. Chem. Res. 2003, 42, 5333-5344. [CrossRef]

8. Ger, A.; Holley, E. Comparison of single-point injections in pipe-flow. J. Hydraul. Div. 1976, 102, 731-746.

9. Fitzgerald, S.; Holley, E. Jet injections for optimum mixing in pipe-flow. J. Hydraul. Div. 1981, 107, $1179-1195$.

10. Forney, L.J.; Lee, H.C. Optimum dimensions for pipeline mixing at a T-junction. Am. Inst. Chem. Eng. 1982, 28, 980-987. [CrossRef]

11. Forney, L.J.; Kwon, T.C. Efficient single-jet mixing in turbulent tube flow. Am. Inst. Chem. Eng. 1979, 25, 623-630. [CrossRef]

12. Egerton, J.S.; Lowe, M.J.; Huthwaite, P.; Halai, H.V. Ultrasonic attenuation and phase velocity of high-density polyethylene pipe material. J. Acoust. Soc. Am. 2017, 141, 1535. [CrossRef] [PubMed]

13. Vijiapurapu, S.; Cui, J. Performance of turbulence models for flows through rough pipes. Appl. Math. Model. 2010, 34, 1458-1466. [CrossRef]

14. van Reeuwijk, M.; Lari, K.S. Asymptotic solutions for turbulent mass transfer at high Schmidt number. Proc. R. Soc. A Math. Phys. Eng. Sci. 2012, 468, 1676-1695. [CrossRef]

15. Cadorin, M.; Morini, M.; Pinelli, M. Numerical analyses of high Reynolds number flow of high pressure fuel gas through rough pipes. Int. J. Hydrog. Energy 2010, 35, 7568-7579. [CrossRef]

16. Mohammed, H.I.; Giddings, D.; Walker, G.S. CFD simulation of a concentrated salt nanofluid flow boiling in a rectangular tube. Int. J. Heat Mass Transf. 2018, 125, 218-228. [CrossRef]

17. Ayhan, H.; Sökmen, C.N. CFD modeling of thermal mixing in a T-junction geometry using LES model. Nucl. Eng. Des. 2012, 253, 183-191. [CrossRef]

18. Zhang, Y.; Sun, B.; Fang, H.; Zhu, D.; Yang, L.; Li, Z. Experimental and Simulation Investigation on the Kinetic Energy Dissipation Rate of a Fixed Spray-Plate Sprinkler. Water 2018, 10, 1365. [CrossRef] 
19. Anselmet, F.; Ternat, F.; Boyer, P.; Amielh, M.; Pietri, L.; Boiron, O. Axial development of the mean flow in the entrance region of turbulent pipe and duct flows. Comptes. Rendus. Mec. 2009, 337, 573-584. [CrossRef]

20. Somkhuean, R.; Niwitpong, S.; Niwitpong, S.A. Upper Bounds of Generalized p-values for Testing the Coefficients of Variation of Lognormal Distributions. Chiang Mai J. Sci. 2016, 43, 672-682.

21. van Reeuwijk, M.; Lari, K.S. Asymptotic solutions for turbulent mass transfer augmented by a first order chemical reaction. Int. J. Heat Mass Transf. 2012, 55, 6485-6490. [CrossRef]

22. Vondricka, J.; Hloben, P.; Schulze Lammers, P. Optimization of Direct Nozzle Injection System for Site-Specific Herbicide Application. In Proceedings of the 2007 ASAE Annual Meeting, St. Joseph, MI, USA, 17-20 June 2007.

23. Lari, K.S.; van Reeuwijk, M.; Maksimovic, C.; Sharifan, S. Combined bulk and wall reactions in turbulent pipe flow: Decay coefficients and concentration profiles. J. Hydroinform. 2011, 13, 324-333. [CrossRef]

24. Lari, K.S.; van Reeuwijk, M.; Maksimovic, C. Simplified Numerical and Analytical Approach for Solutes in Turbulent Flow Reacting with Smooth Pipe Walls. J. Hydraul. Eng. 2010, 136, 626-632. [CrossRef]

25. Akbari, S.; Taghavi, S.M. Injection of a heavy fluid into a light fluid in a closed-end pipe. Phys. Fluids 2020, 32, 17. [CrossRef]

26. Rabinovich, E.; Kalman, H. Generalized master curve for threshold superficial velocities in particle-fluid systems. Powder Technol. 2008, 183, 304-313. [CrossRef]

(C) 2020 by the authors. Licensee MDPI, Basel, Switzerland. This article is an open access article distributed under the terms and conditions of the Creative Commons Attribution (CC BY) license (http://creativecommons.org/licenses/by/4.0/). 